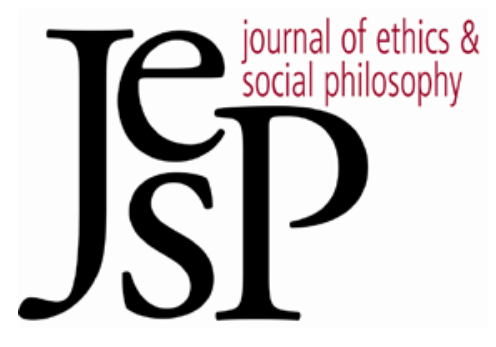

\title{
The Motives for Moral Credit $_{\text {he }}$
}

\author{
BY GRANT J. ROZEBOOM
}

JoURNAL OF ETHICS \&SOCIAL PHILOSOPHY

VOL. 11, NO. 3 | MAY 2017 URL: WWW.JESP.ORG COPYRIGHT @ GRANT J. ROZEBOOM 2017 


\section{The Motives for Moral Credit \\ Grant J. Rozeboom}

\section{I} N MANY CASES, WE CAN SEPARATE THE QUESTION of whether someone succeeded in performing an action of some kind from the question of whether they deserve credit for performing an action of that kind. This is clearly so when we morally evaluate what someone did: we can separate the question of whether what they did was morally right from the question of whether they deserve credit for having done what was right. ${ }^{1}$ For instance, my neighbor has asked me not to make much noise past 10 p.m., since he has to leave early each morning for work. If I keep quiet past 10 p.m., then I do what is morally right. ${ }^{2}$ But it is a further question whether I deserve credit for doing what is right. If I keep quiet just because I happen to be interested in reading my favorite politics blog around 10 p.m. each night, then I do not deserve any moral credit. ${ }^{3}$

This example highlights an important feature of deserving moral credit: one must act from certain kinds of motives and not others, what we can simply call "the right kinds of motives." The reason why I do not deserve credit in the example, it seems, is that I am moved only by my desire to read the blog and not by any concern to abide by my neighbor's request for more sleep. I do not act from the right kinds of motives. In this way, deserving moral credit contrasts with deserving other kinds of credit, such as credit for a piece of academic work or credit for completing a project for one's employer, which do not similarly require certain forms of motivation and not others.

\footnotetext{
${ }^{1}$ In taking the concept of deserving credit as fundamental, I am taking seriously the "ledger" metaphor suggested by Michael Zimmerman (1988, ch. 3) and others. I am drawn to this metaphor because, as stated above, I think the idea of deserving moral credit is just one specification of the broader idea of deserving credit for doing a certain kind of thing. It is a good question how much we can learn about moral credit by appealing to this broader idea of deserving credit. I do think that the notion of moral praiseworthiness associated with moral credit can only be understood in terms of moral credit, and not the other way around, as Michael McKenna (2012: 43-45) seems to suggest.

2 By "morally right," I mean more than "morally permissible." I mean to refer to actions that we in some sense morally ought to do. Keep in mind that these may include supererogatory actions - see Massoud (2016).

3 Some philosophers would put this point by saying that I am "morally praiseworthy" for what I do, or that I have performed an action that has "moral worth." I find those terms misleading. Some actions are morally praiseworthy but not morally creditworthy because they are both extraordinarily difficult and not done from the right motives, and some actions are morally creditworthy but not morally praiseworthy because they are so mundane. The term "moral worth" was initially used by Kant (2002/1785: 13-15) to set apart actions by which we constrain ourselves in the face of contrary inclinations to do our duty, which is a narrower class of actions than those for which we deserve moral credit. I thus will continue using "deserve moral credit" or "morally creditworthy."
} 
What does it take, in general, to act from the right kinds of motives those that are required (and perhaps sufficient ${ }^{4}$ ) for deserving moral credit? An answer to this question should account for how the right kinds of motives involve responding to both the morally relevant reasons (the reasons why one's action is morally right) and the morally relevant individuals (the people, animals, ecosystems, etc. implicated in one's action). Recent theories of the right kinds of motives have tended to prioritize responding to moral reasons. ${ }^{5}$ They try to understand the response to individuals that moral credit requires in terms of responding to moral reasons. I want to propose looking at things the other way around $-\mathrm{a}$ theory that prioritizes responding to individuals, and thus accounts for how moral credit involves responding to moral reasons in terms of our proper response to individuals. ${ }^{6}$

At issue between these two views is the question of how our appropriate attitudes of regard for others (such as respect and care) figure into the right kinds of motives. ${ }^{7}$ These attitudes are how we properly respond to individuals and, I will argue, they involve more than just responding to moral reasons. A reasons-first view must contend that these attitudes figure into the right kinds of motives only derivatively, i.e., only to the extent that they involve motivation by moral reasons. If we are moved by moral reasons without holding these attitudes toward others, we are no less deserving of moral credit. An individuals-first view denies this, and contends that our motives are lacking whenever we fail to be guided by these attitudes, even if we are yet moved by the moral reasons.

${ }^{4}$ It may not be sufficient: some speak of a distinct "control condition" on moral creditworthiness, where what they have in mind are general agential conditions for morally responsible agency that are shared by creditworthy and blameworthy agents. Others speak of how moral creditworthiness sometimes depends on the effort required to do what is right - see, e.g., Smith (1991) and Sorensen (2009). Amy Massoud (2016) argues that, instead of effort, deserving moral credit depends in part on acting rightly in the face of contrary reasons.

5 See, especially, Arpaly (2003; 2015), Arpaly and Schroeder (2013), and Markovits (2010). See also Hills (2009: 113-19) and, keeping in mind the complication mentioned above in $\mathrm{n} .4$, Massoud (2016).

${ }^{6}$ You might imagine a similar debate between Kantian moral theories that prioritize the Formula of Universal Law (e.g., Korsgaard (1996a; 2008)) and those that emphasize the Formula of Humanity (Velleman (1999); Hill (1992; 1997)). I return to this analogy below in n. 32.

7 David Shoemaker (2013) would understand this in terms of his distinction between assessments of answerability and assessments of accountability. Answerability is concerned with the reasons an agent took into account in acting as she did; accountability (which I think encompasses what I am calling "moral credit") is concerned with the quality of an agent's regard for others. That distinction seems right so far as it goes, but it leaves open one of the main questions of this paper: is acting on the basis of moral reasons sufficient for having high-quality regard for others? Shoemaker would say "no," and I agree, but his own account of high-quality regard for others, which is rooted in empathy, does not make room for many of the attitudes (especially attitudes of respect) that, on my view, constitute appropriate forms of regard for others. This means that he does not have an explanation of why acting in response to moral reasons is insufficient for deserving moral credit in cases in which some non-empathic attitudes are called for. 
To evaluate the prospects of an individuals-first view, then, we need to focus on cases in which agents fail to be guided by appropriate attitudes of regard for others even though they are moved by moral reasons. ${ }^{8}$ We need to consider whether their motives are ever lacking in these cases (for the purposes of deserving moral credit), which would support an individuals-first view and challenge a reasons-first view. And we need to consider whether their motives are ever adequate in these cases, which would support a reasons-first view and challenge an individuals-first view. As I discuss below, there seem to be compelling examples on both sides.

If that is right, then we need to figure out which view better deals with the cases that seem to challenge it. I will develop an individuals-first view, which I dub the "Moral Attitudes" account, and argue that it is more successful on this measure than the most promising reasons-first views, which I gather under the heading of the "Moral Reasons" account. In section 1, I explain the Moral Attitudes account, using a general picture of the psychology of individual-directed attitudes that draws on Stephen Darwall's (2002; 2006) work. This will allow me to clarify how being guided by appropriate attitudes of regard goes beyond being moved by moral reasons and, in turn, how the Moral Attitudes account contrasts with the Moral Reasons account. In section 2, I address the challenge for the Moral Attitudes account, using a case in which the motives of someone who is moved by the moral reasons seem sufficient for him to deserve moral credit even though he is not guided by any appropriate attitudes for others. I argue that our judgment that he deserves moral credit rests on the hidden presumption that he is guided by such attitudes, and that this presumption likely hides behind other, similar cases. (I also address the related worry that my account ignores those aspects of morality that are thought to be impersonal in light of the sorts of cases that generate the nonidentity problem). In section 3, I consider challenges for the Moral Reasons account, drawing on a case in which an agent's motives seem lacking because she fails to be guided by attitudes of care for others even though she is moved by the moral reasons. I argue that the Moral Reasons account's attempts to make sense of this case fall short, even when we make a friendly Kantian modification to the account. The Moral Attitudes account thus emerges as the most promising view of the right kinds of motives.

\footnotetext{
8 What about examples in which someone's motives are lacking because his motives fail to incorporate moral reasons even though he is guided by appropriate attitudes? As I discuss below, in section 2, I think that once we understand what the relevant attitudes are - in particular, how different attitudes are appropriate toward different kinds of individuals - it becomes implausible to think that someone could be guided by the proper attitudes and fail to be moved by moral reasons. Now, this result depends in part on what the moral reasons actually are; my suspicion is that, insofar as our verdicts about what the moral reasons are diverge from the considerations on which we act in being guided by the proper attitudes, it becomes less plausible to think that deserving moral credit requires motivation by moral reasons.
} 
1.

To develop an account of the right kinds of motives, we need to specify a general form of motivation that is plausibly present in the wide range of cases in which individuals seem to deserve moral credit for what they do. In this section, I say a bit more about this general constraint on theorizing about the right kinds of motives, and I develop the Moral Attitudes account, which claims that an agent acts from the right kinds of motives to the extent that she is guided by morally appropriate attitudes of regard for those pertinently involved with her actions. ${ }^{9}$

A theory of the right kinds of motives is, first and foremost, a theory of a certain way of being motivated. In theorizing about the right kinds of motives, we thus cannot appeal to such things as an agent's physiological states (such as hunger) or moods (such as sadness). But we can appeal to such things as his desires and intentions. ${ }^{10} \mathrm{~A}$ general principle that seems to capture the relevant distinction is this: if something serves as the right kind of motive for some given action, then it figures into the "rationalizing" explanation of that action - the explanation of why the agent acted as he did that renders his action intelligible from his point of view. An agent's hunger and moods do not help constitute his rationalizing point of view, at least not directly, while his desires and intentions do (along with his attitudes of regard for others, as I argue below). ${ }^{11}$ Thus the latter, but not the former, can rationalize his action and serve as its motives. 12

It is also now commonly accepted that a theory of the right kinds of motives should not require an agent to believe that her action is morally right, contrary to some ways of understanding the Kantian ideal of acting "from

\footnotetext{
${ }^{9}$ McKenna (2012, ch. 3) sometimes states his view in a way that seems similar to my Moral Attitudes account, insofar as he emphasizes the importance of attitudes of regard for others in determining an agent's moral creditworthiness. But he does not develop an account of what exactly these attitudes are and how they figure into an agent's motives, as I try to do here, and, more importantly, he ultimately seems to accept a version of the Moral Reasons account; see esp. McKenna (2016: 248-49).

10 This is not to say that all of the desires and intentions that guide an agent will serve as her motives. Some of them may be a part of what makes her action of type $T$ a $T$-action, and if so, then it may not make sense to think of them as among her motives for $T$-ing. Thanks to Allen Wood for this clarification.

11 Philosophers following Donald Davidson (2001), including Michael Smith (2004), think that the relevant parts of an agent's point of view are constituted only by pairings of her desires and beliefs, but I will argue below that an agent's rationalizing point of view can be understood more broadly to include the attitudes of regard by which she values herself and others.

12 This may be one reason why, following Markovits (2010), we should think it is a mistake to understand acting from the right kinds of motives in terms of character states or other features of an agent's mind that we can understand only in terms of their temporal and/or counterfactual durability. Rosalind Hursthouse (2000) disagrees, although it is not clear to me if she rejects this general constraint on theories of the right kinds of motives or disagrees about what rationalizes actions, as Michael Stocker (1981) does.
} 
duty." Consider the commonly discussed case of Huck Finn: despite thinking that he will have hell to pay, Huck helps the runaway slave, Jim, to escape, apparently out of a sense of sympathy for Jim. Huck seems to fully act from the right kinds of motives - more so, anyway, than if he had helped Jim to escape simply to make Jim feel burdened to repay the favor - even though he thinks that he is acting wrongly. This suggests that we can act from the right kinds of motives even if we do not think that our action is right. ${ }^{13}$ While more could be said about this case and what follows from it, I am going to accept this verdict as it stands, since (as I discuss later on) it is an important part of what motivates the Moral Reasons account.

With those two constraints in mind, let us explore the central ideas of the Moral Attitudes account. ${ }^{14}$ Begin with the idea of being motivated by individual-directed attitudes of regard. To explain this idea, we should first clarify what goes into maintaining these attitudes and then consider how they can motivate our actions (i.e., how they can figure into the rationalizing explanations of our actions). What is distinctive about these attitudes is that they are ways of valuing or appreciating objects without turning them into objects of desire. We value and appreciate people, works of art, the wilderness, nonhuman animals, institutions, and much more. In so valuing these things, we do not thereby desire them - to possess or realize them in some way. ${ }^{15}$ Instead,

13 See, e.g., Herman (1993). It is a good question whether we can understand the Kantian motive of duty in a way that avoids this problem. For instance, my description below of attitudes of respect seems to provide a plausible picture of how one can be motivated by duty without having to think of one's action as morally right. But I will set this matter aside here, since I am focused on displacing the Moral Reasons account, not on evaluating the Kantian views that the Moral Reasons account is designed to supersede.

14 Many philosophers think that we need a further, "no accidents" constraint, along the following lines: our theory of the right kinds of motives should explain why it is that, when an agent is moved by the right kinds of motives to do what is morally right, it is no accident that she does what is right. While I do not disagree with this general idea, I do not think that it places a further constraint on our theories of the right kinds of motives. For there are several independently plausible ways of understanding the general idea of a non-accidental connection between an agent's motives and the fact that she does what is right. Here are five examples: Counterfactual: It is no accident that one does what is right just in case; holding fixed one's motives, one would do what is right in similar alternative circumstances. Intention: It is no accident that one does what is right just in case one does what is right from an intention to do what is right. Intentional: It is no accident that one does what is right just in case one intentionally does what is right. Reason: It is no accident that one does what is right just in case the fact that one's action is right is one of the reasons why one does it. Relevance: It is no accident that one does what is right just in case one's reasons are relevant to the rightness of one's action. Since these are all independently plausible notions of non-accidentally doing what is right (given one's motives), the relevant ones will simply be those that are accommodated by our best theory of the right kinds of motives.

15 See Anderson (1993), Velleman (1999) and my discussion of Velleman's view, below. This is also in line with Kant's idea of regarding something as an "existent" end (Kant

(2002/1785: 46). Of course, Kant seems to think that the only existent end is humanity qua 
we are disposed to think, act, and feel about the objects in various ways, which may involve desiring certain outcomes for the objects but also involves a wider constellation of thoughts, motives, and feelings about them (Scheffler (2010)). For any given attitude, this constellation of thoughts, motives, and feelings is unified by its focus on some object and is explained by the underlying psychological state that the attitude consists in, i.e., this underlying state explains why the attitude disposes us to think, feel, and act in certain ways toward its object.

To illustrate these points, let us consider how Darwall characterizes interpersonal respect and care. Attitudes of interpersonal respect consist in the psychological state of authority-focused norm acceptance, i.e., the acceptance of norms that call for heeding someone's authority (Darwall (2006, ch. 7)). The more general state of norm acceptance involves a distinctive mode of motivation and deliberation, whereby we feel constrained to follow certain rules and bring them to bear in our deliberations even when doing so does not serve any of our independently desired aims. ${ }^{16}$ Accepting norms that call for heeding someone's authority focuses our attention on how she can use her authority, and thus constrains us from interfering in matters within her discretion and ignoring her decisions and demands. Authority-focused norm acceptance also involves certain emotions, such as feeling guilty for violating the respected individual's authority and feeling indignant at others for doing so.

Attitudes of interpersonal care, by contrast, consist in the psychological state of sympathetic concern for others (Darwall (2002, ch. 3)). This state seems to be closely tied to the form of empathy that involves imagining what it is like for someone to be in a certain condition. ${ }^{17}$ In empathizing with someone in this way, we become disposed to feel anxious about obstacles to his welfare, to desire that these obstacles be overcome and to feel distressed when they are not (ibid.: 63-69)). Being sympathetically attuned to him and his plight makes us both emotionally and practically concerned for his welfare.

Both attitudes thus involve a characteristic pattern of thoughts, motives, and feelings about their objects that we can understand in terms of the attitudes' underlying psychological states: the state of authority-focused norm acceptance for interpersonal respect, and the state of sympathetic concern for interpersonal care. This suggests that we can tell similar stories about a wider range of individual-directed valuing attitudes. For instance, when we think about an attitude of care for animals, we could posit a form of sympathetic concern that, like interpersonal care, is fueled by an empathetic imagining of what it is like for the animal to be faced with a certain plight. Aesthetic modes of valuation seem to underlie certain forms of nonpersonal respect, such as

rational nature. But, regardless, you might say that, in respecting and caring about this wide range of objects, you are regarding them as existent ends.

16 I take this to be a relatively uncontroversial general statement about norm acceptance that is consonant with many recent accounts of norm acceptance and social norms; see, e.g., Bicchieri (2006), Sripada and Stich (2007), Darwall (2006, ch. 7) and Railton (2006).

${ }_{17}$ Care ethicists have also emphasized the connection between care, sympathy and certain forms of empathy - see, e.g., Noddings (1984) and Benhabib (1985). 
respect for a wilderness (as being untouched by human hands). Again, what matters is that these attitudes all share the following general structure: they involve being disposed to have certain thoughts, motives, and feelings about their objects, and these various object-focused dispositions can be explained by the attitudes' underlying psychological states.

You might wonder at this point what makes this very wide range of attitudes all individual-directed in the relevant sense. I should emphasize, first, that I am providing a broad characterization of these attitudes so that they can include, not just interpersonal attitudes of respect and care, but also, as I just mentioned, the various forms of appropriate regard we might hold toward other creatures and things. Second, I think that even though norm-constituted attitudes such as respect and sympathy-constituted attitudes such as care have different structures, they are all individual-directed insofar as the individuals toward whom they are directed serve as the ultimate focus of the thoughts, motives, and feelings that the attitudes involve. But you might worry that norm-constituted forms of respect differ from sympathy-constituted attitudes of care precisely because they seem less directly concerned with the individuals toward whom they are directed. I agree in one way but not another. I admit that many forms of respect do not require the sort of acquaintance and attention to their objects that many forms of care (and love) require. But this does not make those attitudes of respect any less individual-directed. They still take individuals as their objects, given that the focus of the thoughts, motives, and feelings they involve are the individual objects themselves.

What we want to know now is how these attitudes can motivate us, and for that we should focus on how they prompt us to act (or refrain from action). Different attitudes do this in different ways, depending on their underlying psychological structure. To use the above example of interpersonal respect, which consists in the state of authority-focused norm acceptance, maintaining an attitude of respect toward others will involve giving default weight to their decisions and demands in one's practical reasoning, and refraining from taking up practical questions that they alone have authority to settle. This is what follows from the fact that such respect consists in a kind of norm acceptance directed toward authority figures. Or to consider interpersonal care, when we are sympathetically concerned for others, we will strongly desire that they are not harmed by potential threats to their wellbeing and, if we are in a position to do so, to help them deflect these threats. So, attitudes of respect and care can prompt action through the different ways they shape our desires and practical reasoning, and how they do so depends on the differing psychological states they consist in. To generalize, we could say that we are motivated by some individual-directed attitude of regard when (i) we maintain that attitude, (ii) we are motivated to pursue or avoid some course of action in virtue of that attitude's underlying psychological state (by applying a norm, forming a desire, etc.) and (iii) we follow through on that motive.

But now we face the following challenge: given that we can provide a rationalizing explanation of an agent's action simply by appealing to the more 
proximal motives mentioned in (ii), without appealing to how the agent's individual-directed attitude generated those motives, it remains unclear why we should think of the agent as being motivated by the attitude itself. After all, we do not generally have to cite the psychological history of the desires or intentions from which an agent acts in order to rationalize her action. So what is different about the role that individual-directed attitudes play in prompting an agent's actions through generating desires, intentions, and the like? To answer that question, we need to see how these attitudes figure into a certain kind of rationalizing explanation, one that appeals to those for whom, or for whose sakes, an agent acts. ${ }^{18}$

Someone asks me, "Why are you rushing home?" and I respond, "For my child; we need to work on his science project before dinner." Or you ask, "Why do you always call home on Sundays?" and I say, "For my parents' sakes; they worry about me if I don't." Or I defend myself against the charge that my action is selfish by saying, "I'm doing it for him, not me!" In rationalizing my actions by appealing to certain individuals for whom (or for whose sakes) I act, what am I saying about my actions? As Velleman (1999: 355-60) argues, I am not simply providing an abridged version of a longer story about the goals involving those individuals that my action is meant to serve. I am saying that, beyond the various goals I am pursuing, I am acting out of an orientation to the individuals themselves. We cannot fully understand my action without seeing it as an expression of my direct orientation to them - without seeing that, as Michael Thompson (2004) puts it, the individuals themselves, and not just the goals that involve them, appear on my "practical radar" (346). This orientation to the individuals themselves is given by my attitudes of regard for them, such as respect and care. Thus, in rationalizing my action in terms of those for whom (or for whose sakes) I act, it seems that I am rationalizing my action in terms of my individual-directed attitudes, and not just the more proximal motives - the desires and intentions - that these attitudes have generated.

Two main considerations substantiate this conclusion: first, no specification of an agent's motives that leaves out her attitudes of regard for others seems to fully capture what is expressed in saying that she acts for their sakes, and second, rationalizing her action explicitly in terms of her attitudes of regard for others seems to express the same thought that is conveyed by saying that she acts for their sakes. To illustrate using one of the above examples: in rushing home to help my child, I might be moved by a desire or intention to keep my promise to him, which is likely nested in a more general desire or intention not to violate his trust. If this is all we say about my motives, we seem to fall short of the idea that I am acting for his sake. For I might desire not to break

18 It is important to be clear that I am focusing only on rationalizations that appeal to the individuals for whose sakes we act, and not all claims we make about acting for the sake of individuals. We can often sensibly claim that so-and-so acted for someone's sake in a weak sense - say, when they are immersed in their work and their job requires providing a benefit to someone - when it would not make sense to rationalize their action in that way. Thanks to an anonymous referee for drawing my attention to this point. 
his trust simply out of an attachment to some moralistic ideal of being a good parent, or simply because I have a strong desire to deal honestly with others. What we need to fill in the thought that I am acting for my child's sake, it seems, is the idea that my interest in not violating his trust is rooted in an attitude of concern for him. And once we have that idea - that I am guided by an attitude of care for my child - we seem to have all that we need. The statement, "I'm rushing home to help my child with his science project because I care about him," seems to capture all of what is expressed in the rationalizing explanation, "I'm rushing home for my child's sake, to help him with his science project." 19

Thus, an agent's individual-directed attitudes of regard are a part of what motivates her when she acts on the more proximal desires and intentions that these attitudes generate, since these attitudes are what we appeal to when we rationalize her action in terms of the individuals for whose sakes she acts. What we need to consider next in developing the Moral Attitudes account is the idea that these attitudes can be more or less morally appropriate. Whether some individual-directed attitude is morally appropriate depends, in large part, on the kind of individual that serves as its object. The relevant facts about individuals are given by the presuppositions of the attitudes that are held toward them. For instance, Darwall (2006) argues that holding an attitude of interpersonal respect toward someone presupposes that she is able to hold herself to the same sorts of demands (from others) that you take her to have the standing to issue; Velleman (1999) contends that a basic form of love presupposes that its object is capable of reciprocating love; and Darwall's (2002) account of care (discussed earlier) suggests that, in being sympathetically concerned for some individual, you presuppose that she (or it) can be harmed. These attitudes are appropriate only if they are held toward individuals that fit their presuppositions.

It is also important to see that, relative to the kinds of individuals that fit the presuppositions of these attitudes, some are more fundamentally appropriate than others. Suppose that a parent cares deeply for his adult child but pays her little respect. He feels free to interfere with her affairs whenever doing so is required to preserve her interests, as he more appropriately did when she was a young child. His attitude of care for her is not entirely inappropriate after all, we may often reasonably feel the urge to meddle in the affairs of loved

\footnotetext{
${ }_{19}$ More argument is needed to fully generalize from this example. One complication is that sometimes when we are guided by attitudes of respect for others, no corresponding "for her sake" rationalization sounds right. If I want to help someone with a difficult task but she tells me to leave her alone, and I leave her alone out of respect for her, it seems odd to say, "I'm leaving her alone for her sake." My suspicion is that the "for her sake" locution tends to call to mind care-like attitudes more readily than respect-like attitudes. But this does not imply that attitudes of respect rationalize our actions any less than attitudes of care do, given that both kinds of attitudes guide us in the same general way and are individual-directed.
} 
ones to better their lives - but it should be constrained by the more fundamentally appropriate attitude of respect that we hold toward adult persons. ${ }^{20}$ What determines which attitudes are fundamentally appropriate, relative to the kinds of individuals that serve as fitting objects? We do not need a full answer to this question for the purposes of this paper, and so I am happy to remain open to different answers. One important factor to consider is how certain attitudes can help us solve (or instead exacerbate) the basic problems we tend to face when we encounter individuals of a certain kind. For instance, following Rousseau, it seems that one of the fundamental problems we face when encountering other adult persons is the problem of inflamed amour-propre-our tendency to become preoccupied with being well regarded by others, to the point of wanting to demean and dominate them in order to seem more estimable by comparison. Certain attitudes of respect help to solve this problem..$^{21}$ Other problems afflict our interactions with other kinds of creatures and so call for different attitudes. At any rate, my main point here is that a full account of the moral appropriateness of individual-directed attitudes will consider both what the attitudes presuppose about their objects (and whether their objects fit those presuppositions) and which attitudes are most fundamentally appropriate relative to their fitting objects.22

The last piece of the Moral Attitudes account is the idea that our morally appropriate attitudes should extend to all of the individuals pertinently involved with our actions. What is this idea of pertinent involvement? I think it is a normative, deliberative notion: an individual is pertinently involved with your action just when she is someone you should have in mind in the deliberations leading to that action. This is not to say that being guided by morally appropriate attitudes requires deliberation; it is just to point to the individuals you should have in mind if you were to deliberate. This standard is sensitive to, among other things, the operation of what Joseph Raz (1986; 2006) calls "preemptive" reasons in our practical reasoning. Such reasons not only favor certain courses of action, but also replace and exclude other considerations. For example, when we are required by a legitimate authority-figure to complete some task, their demand not only gives us a reason to complete that task, but also displaces the considerations bearing on the justification of their authority

20 Substantiating this point would require mounting an argument against care ethicists who allege that, at least for persons, attitudes of care are more fundamentally appropriate than attitudes of respect, in line with what Darwall (2014) claims about interpersonal relations.

${ }^{21}$ See, for relevant commentaries on Rousseau's work, Cohen (2010: 102-3) and Neuhouser (2014: 186-89).

22 This feature of my account enables it to avoid the criticism that Arpaly (2015) directs against a Kantian theory of the right kinds of motives centered on the Formula of Humanity. She worries, in effect, that such an account cannot explain why attitudes of care that sometimes lead to paternalism (of the sort discussed above) can ever help constitute the right kinds of motives (2005: 103-4). My account says that these attitudes are somewhat appropriate, insofar as they are held toward a fitting object, but not fully appropriate, insofar as they are not constrained by a more fundamentally appropriate attitude of respect. 
and excludes a range of conflicting considerations ("But I'm tired!"). The displaced and excluded considerations might refer to individuals that, although they seem to be involved with our course of action, are not among the individuals we should have in mind in our deliberations, given how the preemptive reasons have scuttled the considerations referring to them. This is just one example of the kinds of factors that determine which individuals we should have in mind in our deliberations and, thus, are pertinently involved with what we do.

We can now state the Moral Attitudes account: an individual acts from the right kinds of motives to the degree that she is motivated by the morally appropriate attitudes of regard for those pertinently involved with her action. You will notice that my formulation of this account suggests that acting from the right kinds of motives, and being guided by the morally appropriate attitudes, comes in degrees. This is because I agree with advocates of the Moral Reasons account that we can be more or less morally creditworthy (as I discuss below), and this seems to be primarily due to the fact that acting from the right kinds of motives comes in degrees. On my account, this gradation exists along two primary dimensions: the individual-directed attitudes by which we are motivated will be more or less morally appropriate, and these attitudes will be held toward more or fewer of those who are pertinently involved with one's action. ${ }^{23}$ This means that an agent could be motivated by a fully morally appropriate attitude toward someone pertinently involved with her action but still not fully act from the right kinds of motives because many others are pertinently involved with her action. Conversely, someone could be concerned with all of those who are pertinently involved with her action but still not fully act from the right kinds of motives, because her attitude toward these individuals is morally inappropriate.

Before turning to contrast the Moral Attitudes account with the Moral Reasons view, we should briefly note how the Moral Attitudes account satisfies the two general constraints that I laid out at the beginning of this section. First, it appeals only to aspects of an agent's motives: it appeals to her individualdirected attitudes of regard, which figure into the rationalizing explanations of her actions that refer to the individuals for whose sakes she acts. Second, it does not require that an agent believe in the moral rightness of her actions. We

23 You might think that we should not be concerned here only with the number of individuals that one should have in mind in one's deliberations, but also with how those individuals should be prioritized or emphasized in one's deliberations. On my view, the proper prioritization of individuals should be achieved by the interaction of the appropriate attitudes held toward those various individuals, but I cannot fully explore this matter here. Thanks to R. J. Leland for pointing out this complication.

There also may be further dimensions (beyond these two) along which we can measure the extent to which someone is guided by appropriate attitudes of regard for others. For instance, perhaps an attitude that is appropriate relative to an agent's false beliefs will be less appropriate than an attitude that is appropriate in light of the facts, but still more appropriate than an attitude that is inappropriate in light of both the facts and the agent's false beliefs. Thanks to an anonymous referee for pointing out this possibility. I have chosen to focus only on the two dimensions that matter most for capturing the cases discussed in this paper. 
can be moved by morally appropriate individual-directed attitudes without believing that our actions are morally right, given that these attitudes can shape our desires and practical reasoning without this belief. Think, for instance, of how Huck is moved by an attitude of sympathetic concern for Jim, even though he does not believe that helping Jim is what he morally ought to do. Now, this point is delicate when we focus on attitudes of respect that consist in authority-focused forms of norm acceptance; for, on some non-cognitivist metaethical views, such norm acceptance may amount to believing that one's action is morally right. But I take it that the commonly accepted claim that the right kinds of motives do not require believing in the moral rightness of one's actions assumes a more cognitivist picture of moral belief. At least, without this cognivitist assumption, the claim that acting from the right kinds of motives does not require believing that one's action is right is much less compelling. So I think that the Moral Attitudes account goes far enough toward satisfying this second constraint on theorizing about the right kinds of motives.

2.

We now need to begin testing the Moral Attitudes account. In this section, I contrast it with the Moral Reasons account, and I consider how the Moral Attitudes account deals with the kinds of cases that seem to challenge it - cases in which agents who are not guided by individual-directed attitudes of regard still seem to be morally creditworthy in virtue of being moved by the moral reasons. I argue that our reactions to these cases rest on a hidden presumption (contrary to the stated facts of the cases) that the agents in them are guided by morally appropriate, individual-directed attitudes.

Let us begin by considering the Moral Reasons account, which is motivated by cases, such as Huck Finn's, in which agents clearly seem morally creditworthy even though they do not act in line with what they believe they morally ought to do. Even though agents in these cases are not moved by a concern with doing what is morally right, they do seem to be moved by a concern with what makes their actions morally right. That is, they act on the basis of the reasons why their actions are morally right. For instance, Huck seems to be motivated by the important fact that his friend, Jim, is in serious danger.

Proponents of the Moral Reasons account propose that this must be how Huck acts from the right kinds of motives. ${ }^{24}$ Huck does not need to be concerned with the fact that his action is right; he just needs to act on the basis of the reasons why it is right. They move from this conclusion to a fully articulated version of the Moral Reasons account in two steps. First, they claim that what matters is being noninstrumentally motivated by the right-making factors (i.e., the

24 As I mentioned above, the Moral Attitudes account offers an alternative explanation here, appealing to Huck's attitude of care for Jim. 
reasons why one's action is right), and not just being motivated by them simpliciter. This qualification is needed to rule out agents who are only indirectly or instrumentally concerned with the right-making factors. ${ }^{25}$ How exactly should we understand the idea of being noninstrumentally motivated by the right-making factors? Markovits (2010) and Arpaly and Schroeder (2013) agree: it consists in being motivated to realize the right-making features of one's action as an end and not just a means to some further end. Arpaly and Schroeder further specify the relevant form of noninstrumental motivation: they say it consists in being moved by intrinsic desires, which they think are a distinctive kind of psychological state associated with our reward-learning system. But the basic idea that these theorists share is that being noninstrumentally motivated by some right-making factor consists in pursuing its realization as an end.

The second step taken by proponents of the Moral Reasons account is to claim that an agent acts from the right kinds of motives to the degree that she is noninstrumentally motivated by the right-making factors. This is in part a matter of how much overlap there is between the factors by which an agent is noninstrumentally motivated and the reasons why her action is morally right. It is also a matter of the strength of the relevant motivations and the extent to which an agent's action exhibits their strength. For instance, Arpaly and Schroeder argue that an agent whose action manifests weak intrinsic desires for the right-making factors would act from the right kinds of motives to a lesser degree than someone whose action manifests strong intrinsic desires to realize those factors. 26

This brings us to the official formulation of the Moral Reasons account: an agent acts from the right kinds of motives to the degree that she is noninstrumentally motivated by the right-making factors. ${ }^{27}$ This is an elegant account of acting from the right kinds of motives. It draws on just a couple of basic ideas in the philosophy of action and moral philosophy - the idea of a motivating reason and the idea of a right-making reason - and in doing so, it seems to satisfy the two constraints that come to bear on theories of the right kinds of motives. It appeals only to aspects of an agent's motives - specifically, the features of her

${ }^{25}$ For instance, a mayoral candidate helps his neighbor, Sally, to clean up her yard, and his reasons for doing so include the fact that Sally clearly needs his help and has asked for his assistance. These are at least some of the reasons why it is morally right for him to help Sally. But suppose that he cares about giving Sally the help she needs and requests from him only because he wants Sally to vote for him, and he thinks that she will be more likely to vote for him if he helps her in this way. So, although he acts on the basis of the right-making factors, he does so only instrumentally.

26 Markovits (2010: 238, n. 66) makes a similar claim.

27 Put this way, the Moral Reasons account seems to require that an agent actually do what is morally right. But that is not quite right: an action could have a right-making feature by which an agent is motivated even though it also has several wrong-making features that, on balance, make her action morally wrong; see Markovits (2010: 240-41)). In many such cases, it is natural to think that the agent does the wrong thing from the right kinds of motives. 
action that she noninstrumentally aims to realize - and, as previously discussed, it does not require that an agent believe in the moral rightness of her action. We can be moved by the reasons why our action is right without thinking that it is right. 28

How exactly do the Moral Attitudes and Moral Reasons accounts differ? They differ because we can be noninstrumentally motivated by the right-making factors without being guided by morally appropriate, individual-directed attitudes. Below I discuss some examples that illustrate this possibility, but we can provide an initial explanation of it now: being noninstrumentally motivated by the right-making factors does not require the psychological states that underlie individual-directed attitudes (such as respect and care) and the full range of dispositions that these attitudes involve. This means that, on the Moral Reasons account, we can act from the right kinds of motives without being guided by individual-directed attitudes, and on the Moral Attitudes account, this is not so. Now you might wonder whether, conversely, we could be guided by the morally appropriate, individual-directed attitudes without being noninstrumentally motivated by the right-making factors. I doubt it, but all that matters here is that, given the substantive claims that Moral Reasons theorists make about which agents do or do not act from the right kinds of motives, they are committed to thinking that agents guided by morally appropriate, individualdirected attitudes will be motivated by the right-making factors. For instance, Arpaly (2015) claims that the sorts of anti-paternalistic considerations that animate agents guided by attitudes of interpersonal respect are right-making factors, and both Arpaly (2003) and Markovits (2010) think that considerations about the wellbeing of others, which are front of mind for those guided by attitudes of care, are right-making factors.

At this point, proponents of the Moral Reasons account may suggest that what makes certain individual-directed attitudes morally appropriate is the fact that they involve motivation by right-making factors, which would seem to make the Moral Attitudes account collapse into the Moral Reasons account. ${ }^{29}$ But, first of all, this collapse does not follow: even if it were true that the moral

28 It is worth noting that, while Markovits and Arpaly and Schroeder accept the Moral Reasons account as stated here, there are important differences between their views. But these differences do not bear on the main disagreement between the Moral Attitudes and Moral Reasons accounts.

29 Arpaly and Schroeder (2013) might go further and insist that morally appropriate attitudes ultimately consist in intrinsic desires for the fundamental right-making properties. Consider, for instance, their response (ibid., ch. 4) to Velleman's and Darwall's theories of love and care. But I think that my account above of individual-directed attitudes should make clear that, even if these attitudes do involve intrinsic desires to realize right-making factors, these attitudes also involve more than that. Respect consists in norm acceptance, which, as Darwall (2006, ch. 7) convincingly argues, is motivationally distinct from desire, and care involves being sympathetically attuned to someone's plight, which is not entailed by intrinsically desiring their wellbeing (although it reliably supports such a desire). Moreover (and in line with what I say immediately below), it seems that some morally appropriate attitudes involve intrinsic desires for things other than the right-making factors. 
appropriateness of individual-directed attitudes was determined by the extent to which they involved motivation by right-making factors, the Moral Attitudes account would remain distinct from the Moral Reasons account. For it would remain that agents could be noninstrumentally motivated by the rightmaking factors without being guided by morally appropriate attitudes toward others, given that maintaining such attitudes requires more than being moved by the right-making factors, and the Moral Attitudes account would remain committed to denying that such agents act from the right kinds of motives. Second, it is not plausible to think that the moral appropriateness of individualdirected attitudes is fully determined by the extent to which these attitudes involve motivation by the right-making factors. Morally appropriate attitudes can involve motivation by additional factors, and their moral appropriateness is not generally diminished by the extent to which this is so. Think, for instance, of the morally appropriate forms of love that parents hold toward their children. Parental love does not exclusively involve a concern for right-making factors, but it seems more appropriate than milder attitudes of care that would more closely hew to the right-making factors. Moreover, as I discussed earlier, there seem to be other measures of an attitude's appropriateness than the extent to which it involves motivation by the right-making factors, such as the presuppositions the attitude makes about its object and the kinds of relational problems that it helps us to solve. In sum, I think that we can preserve the independence of the Moral Attitudes account.

Notice also that we could turn the tables and claim that the Moral Reasons account collapses into the Moral Attitudes account. For it is plausible that our sense of what the right-making factors are, when taken as the basis of the right kinds of motives, derives from our tacit understanding of the sorts of factors that would motivate agents who are guided by appropriate, individual-directed attitudes; insofar as the right-making factors diverge from the considerations that would motivate such agents, it becomes less plausible to think that acting from the right kinds of motives consists in being motivated by the right-making factors. This is especially apparent if the proponent of the Moral Reasons account tries, perhaps in response to the kinds of worries I raise below, to modify their account in the following way: an agent acts from the right kinds of motives to the degree that she is correctly noninstrumentally motivated by the right-making factors. If this use of "correctly" has independent meaning - i.e., if it does not just rule out the cases that pose problems for the Moral Reasons view in an ad hoc way - then it will refer to features of an agent's motivations, such as her feelings toward herself and others, that we can only understand in terms of appropriate, individual-directed attitudes. ${ }^{30}$ We have just as much reason, then, to worry that the Moral Reasons account collapses into the Moral

${ }^{30}$ I am not sure that either Markovits or Arpaly and Schroeder would be tempted to modify their accounts in this way. They go to great lengths to explain the idea of acting for the right reasons in more basic terms that do not add further normative criteria; hence, instead of first 
Attitudes account as we do the reverse. Rather than continue down this path, we should just treat these views as independent accounts and focus on the challenging cases they each face.

The Moral Attitudes account is challenged by cases in which agents who are not guided by individual-directed attitudes still seem to be morally creditworthy in virtue of being motivated by the right-making factors. Here is one example: Anthony despises cheating and is deeply committed to being honest. While preparing for an important college entrance exam, Anthony's loyal but unscrupulous friend sends him a cheat sheet. Anthony immediately deletes this email, simply because of his aversion to cheating and strong commitment to honesty. No attitudes of concern or regard for others seem to figure into his motives. Even so, it seems clear that he acts from the right kinds of motives and deserves moral credit, at least to a significant degree. ${ }^{31}$ And the apparent reason why is that he acts on the basis of the reasons why his action is right. $\mathrm{He}$ is noninstrumentally moved by the right-making factors of not cheating and upholding standards of honesty. It thus looks like the Moral Attitudes account wrongly concludes that Anthony does not act from the right kinds of motives, while the Moral Reasons account correctly concludes that he does.

We could imagine a number of similar cases that share the same general features: agents are in a position to easily but wrongly exempt themselves from the constraints and burdens that everyone is expected to bear in some collective endeavor (or social practice, or political institution) in order to derive some special advantage for themselves, but they refrain from doing so precisely because they do not want to cheat (or free ride, or rig the system in their favor). The Moral Attitudes account has trouble making sense of these cases because it looks like the agents in them should be moved by a more impersonal concern for standards of fairness - the sort of concern that is nicely captured by the Moral Reasons account - rather than a personal concern for certain individuals. 32

I admit that the motives of agents such as Anthony should be impartial in these sorts of cases, but that does not mean their motives should be impersonal.

using some qualifier like "correctly," they appeal to the idea of noninstrumental motivation and discuss how the strength of motives can match the strength (or weight) of right-making factors. This is especially true of Arpaly and Schroeder's view, which develops a detailed account of intrinsic desires and their physical basis (2015, ch. 6) and then uses this general conception of intrinsic desire to explain acting from the right motives.

${ }^{31}$ I am grateful to Benjamin Miller for bringing my attention to this objection and example.

32 It is also worth noting that these are the sorts of cases nicely captured by Kant's Formula of Universal Law, and if you accept something like Velleman's (1999) person-centered reading of the Formula of Humanity, then a similar problem arises for the Formula of Humanity. I think that my proposed solution to the problem that these cases pose for the Moral Attitudes account, which appeals to the attitudes of respect that we hold toward those who share in our cooperative endeavors and practices, could also work for Velleman's reading of the Formula of Humanity. But exploring that matter would take us too far afield from the main debate between the Moral Reasons and Moral Attitudes accounts. 
And I think our judgment that Anthony deserves moral credit rests on the hidden presumption that he is motivated by impartial yet personal attitudes of respect for others and himself. Try to maintain the thought that he deserves moral credit while imagining that he holds no attitude of respect toward his fellow test takers, as those who have the standing to demand that he, like them, not access the answer key to the exam, or toward his fellow college applicants, who are expecting to fairly compete with him for admission. ${ }^{33}$ Nor is Anthony guided by respect for himself - the sort of self-respect that would lead him to remind himself that he is not the kind of person who cheats. If you are like me, once you clearly imagine Anthony in this way, and all that remains is his aversion to cheating and commitment to being honest, your confidence in the judgment that he deserves moral credit starts to waver. His motives begin to appear legalistic, fussy, and downright puzzling - why does he care so much about not cheating and being honest, if he does not respect others and himself? Our initial thought that Anthony is not guided by attitudes of respect and care for others (or himself) must have been the product of focusing on the fact that he is not especially concerned with certain individuals who are especially impacted by his action. But that does not imply that he is not guided by attitudes of respect for all those who are taking part in the same collective (test-taking, college-application) endeavors as him, and/or an attitude of respect for himself as someone who is not willing to exploit such endeavors.

This suggests a general way for the Moral Attitudes account to make sense of cases such as Anthony's: in these cases, our judgment that the agent deserves moral credit depends on taking for granted that, in being concerned to avoid some form of cheating or free riding or unfairness, the agent is guided by impartial but still personal attitudes of respect for those he is concerned not to cheat or exploit. The fact that these attitudes are not directed toward some individuals who are especially impacted by his actions, and/or with whom he is familiar, is what generates the false impression that the agent is not at all guided by attitudes of regard for others. Thus, the Moral Attitudes account is able to reach the right verdict about these sorts of cases: agents such as Anthony act from the right kinds of motives in virtue of being guided by appropriate attitudes toward those who share in the collective enterprises that they refrain from exploiting. (We could add that these agents are also guided by attitudes of respect for themselves, but the more salient features of these cases seem to concern the relation between the agents and those who share in their collective enterprises, and so this is what I will focus on moving forward.)

I have a similar response to worries about cases in which agents are in a position to either preserve or diminish abstract values that do not seem to involve any concrete individuals but are still morally important, such that agents can deserve moral credit for acting to preserve or promote these values (e.g., preserving scientific knowledge). My claim is that, in assessing agents in

${ }_{33}$ Note, again, that holding an attitude of respect toward someone does not require being personally acquainted with him in the way that attitudes of care or love tend to require. 
these cases, it is easy to overlook our assumption that the agents are guided by appropriate, individual-directed attitudes (say, toward past or future scientists, and toward those who deserve access to the benefits of scientific knowledge). That is, I think we tend to assume that agents should pursue these abstract values only by being concerned with the people, creatures, and other things in light of which the abstract values have their noninstrumental significance (Anderson (1993, ch. 2)). ${ }^{34}$ But since none of these individuals is especially salient in the agents' minds in these cases, it is easy to look past our belief that the agents are motivated by a concern for them. Or, if we really are making no such assumption, and we are clear about this, then the agents in these cases no longer clearly seem to act from the right kinds of motives. ${ }^{35}$

You might point out that, in order for the Moral Attitudes account to sustain this line of response about Anthony's case and related cases, it must be true that agents such as Anthony could keep an implausibly large number of individuals in mind in the deliberations leading to their creditworthy action (given how the account understands pertinently involved individuals). In response, I should first clarify that an agent in these cases need not think about all of the individuals involved with his action individually, as though each of their faces should flash before his mind. The agent also need not be concerned with the particular plights of all of these individuals, as though he were responsible for attending to each individual's interests. But he can and should have all of them in mind in the same way that, for instance, a teacher can and should have all of his students in mind when he is considering whether to assign a final paper that will involve reading and commenting on paper drafts or instead to just give an exam with short, straightforward questions. The teacher (let us suppose) is thinking of his students in deciding to assign the more work-intensive project, and he does so in virtue of caring about all of them as his students, even though he does not think about them one by one in his deliberations. Similarly, an agent such as Anthony can and should have all of the individuals involved with his action in mind in his deliberations, and he can do so in virtue of respecting all of them, even though he cannot attend to them one by one in his deliberations.

You might also worry that the Moral Attitudes account is too quick to discredit Anthony if we stipulate that he is not at all guided by appropriate attitudes toward others. After all, is there not something to be said for someone who is firmly committed to not cheating and free riding? I certainly would

${ }^{34}$ I recognize that this is a controversial thesis about values, one that I cannot defend here. I should point out that, even if it is false, we could still think that the right kinds of motives require agents to regard individuals as the source of the significance of more abstract values. 35 It is also worth keeping in mind that some impersonal values directly involve concrete objects toward which we can hold appropriate attitudes of regard, what I would call "individualdirected" attitudes. This is true, for instance, of the environment: there are segments of wilderness or ecosystems that I think we can appropriately respect as such. There are no other individuals that need to come into view, on my account, in order for agents to be motivated by appropriate individual-directed attitudes. 
appreciate having such a person around compared to the alternative of someone who maintains no such commitments. But the question is whether they deserve moral credit for acting rightly and, to answer that question, I think much depends on why they care about not cheating or free riding. Do they just happen to have a strong desire not to cheat or free ride, in the same way many individuals have a strong natural urge to avoid large crowds? If so, then I find myself unwilling to give them credit for doing what is right, however much I appreciate that they are committed to avoiding cheating and free riding. Have they always been told to not cheat and free ride and over time internalized this message, in the same way that a child is trained to look both ways before crossing a road? Once again, it seems that they are not morally creditworthy. I suspect that, unless we see that the source of their interest in not cheating and free riding is, at least in part, an attitude of regard for others, our conclusion will remain the same.

My response to Anthony's case (and related cases) leaves untouched a different sort of example that suggests that morally creditworthy motivation should at least sometimes be not just impartial but impersonal. I am thinking primarily of the kinds of cases that generate the nonidentity problem. ${ }^{36}$ Even if you grant that Anthony is motivated by an impartial but still personal concern for those implicated in his test-taking endeavor, you might think that we cannot say anything similar about a case in which an agent's activity impacts future individuals and determines, in part, which future individuals come into existence. How could an agent be motivated by an appropriate attitude of regard for these individuals, if we (and he!) cannot make sense of the thought that he will be benefiting or harming them in acting as he does? For given that their existence depends in part on what he does, they cannot raise a complaint against him that they are worse off than they would be otherwise, because they simply would not be otherwise. So whatever appropriate attitudes guide agents in thinking about future individuals in these kinds of cases cannot consist in individual-directed forms of concern for these future individuals but some more impersonal forms of concern for the abstract values (e.g., human welfare) at stake.

This worry rests on an incorrect understanding of our appropriate attitudes of regard for future persons. The worry presumes that these attitudes primarily consist in a concern with not harming and/or benefiting them. I think - although I cannot argue this point here - that it is more plausible to think of our regard for future persons in terms of their standing as our descendants to receive certain kinds of consideration or due regard from us, that is, in terms of certain rights they hold (Velleman (2008)) or the kind of place they should have in our deliberations (Wasserman (2005)). ${ }^{37}$ Now, you will

\footnotetext{
${ }^{36}$ Many thanks to an anonymous referee for raising this important concern.

${ }^{37}$ Now, there does seem to be an important difference between, for instance, a parent thinking about the difficulties of bringing children into the world and citizens thinking about avoiding
} 
rightly notice at this point that I am taking sides in a substantive debate about the nature of our moral obligations to future individuals, something that you might think that theorists of the right kinds of motives should avoid. I disagree, and so do other theorists of the right kinds of motives. ${ }^{38}$ It is a mistake to think that we can establish theories of the right kinds of motives that are entirely modular with respect to first-order views in normative ethics. Of course, one should go beyond appealing to such first-order views in establishing an account of the right kinds of motives. But that does not imply neutrality with respect to first-order views.

In sum, I think that Anthony's and related cases do not pose a serious problem for the Moral Attitudes account. Our sense that the agents in these cases deserve moral credit rests on the background presumption that they are moved by morally appropriate attitudes toward the individuals pertinently involved with their actions. This means that they act from the right kinds of motives on the Moral Attitudes account.

3.

As I mentioned above, the Moral Reasons account also has a nice explanation of cases such as Anthony's, since it seems clear that the agents in these cases are noninstrumentally motivated by the right-making factors. But other sorts of cases pose a problem for the Moral Reasons account, in which agents' failures to be moved by individual-directed attitudes do seem to diminish their moral creditworthiness, despite the fact that they are noninstrumentally moved by the right-making factors. In this section, I discuss what I think is a representative example of these cases, and I argue that the Moral Reasons account is unable to make sense of it, even with some friendly modifications.

Consider Charity and Carey, who both come to the aid of their neighbor, Ned. Ned has fallen on hard times: he lost his job and is about to lose his home, and so he has set up an emergency yard sale of his belongings. After they come upon his yard sale and talk with Ned, Charity and Carey each decide to help him however they can.

Charity is motivated to help Ned because she is intrinsically drawn to the activity of helping others. This is so in the same way that you might intrinsically enjoy playing the piano, or writing poetry, or coaching baseball. This means that whenever she comes upon an opportunity to help others, she is noninstrumentally motivated to help them. This is what happens when she comes

climate catastrophe for future generations (Wasserman 2005: 132-33). But this difference is orthogonal to the general challenges raised by cases motivating the nonidentity problem, and it points back to my treatment of Anthony's case: some of our individual-directed attitudes are relatively wide in scope and do not require the sort of acquaintance and attention that, e.g., attitudes of familial and friendly love and care require.

${ }^{38}$ For instance, Markovits argues that her version of the Moral Reasons view rules out actutilitarianism (2010: 233-37), and Arpaly (2015) argues that her version rules out certain forms of Kantianism. 
across Ned's yard sale. She sees a chance to engage in the activity of helping someone, and so she comes to be noninstrumentally motivated to help Ned. She pursues helping him as one of her ends.

Carey, by contrast, does not generally enjoy the activity of helping others. But she does have a "big heart" - she normally comes to care for those around her, even if she has only just met them. Thus, when she comes across Ned's yard sale, she feels for him and becomes motivated to help him however she can. Her sympathetic concern for Ned makes her noninstrumentally motivated to help him and so, like Charity, helping Ned becomes one of her ends.

It seems to me that Carey deserves moral credit and Charity does not (or at least, Carey deserves much more credit than Charity), because Carey actually cares about Ned and Charity does not. ${ }^{39}$ Charity is only indirectly concerned with Ned, as someone who presents an occasion for her to engage in the activity of helping others, but Carey is concerned directly for Ned himself. One way of putting the intuitive thought is to say that Charity's attitude is too impartial. It does not directly concern particular persons and their plights.

To see why the Moral Reasons account has trouble with this case, recall that being noninstrumentally motivated by the right-making factors - the rightmaking features of one's actions - consists in pursuing the realization of those factors as an end. So, we should ask: what are the factors that Charity and Carey pursue realizing as ends? For Charity, the answer is: helping Ned in his time of need, for doing this will instantiate an activity that she is intrinsically motivated to pursue. ${ }^{40}$ For Carey, our answer is the same, because her care for Ned motivates her to help alleviate his plight as an end. Now, other factors may noninstrumentally motivate Charity and Carey, but this is the motivating factor that is most straightforwardly entailed by the facts of the case. It also seems to be the only motivating factor that is a plausible right-making factor one that explains why their respective actions are morally right. This suggests that Charity and Carey are noninstrumentally motivated by the right-making factors to the same degree. They both are noninstrumentally motivated by the same right-making factor of helping Ned in his time of need, and this factor seems to have the same relative significance in their deliberations and motives.

39 You might worry that it is important to preserve the thought that Charity deserves some credit for doing what is right, and that the Moral Attitudes account denies this, since she is not at all guided by an appropriate attitude toward Ned. In response, I want to repeat something I said above about Anthony: our verdict depends on why Charity is motivated by the rightmaking factors. Given that she is moved to help Ned just because she happens to enjoy helping others, she does not seem to deserve moral credit. As with Anthony, there is much to appreciate about Charity, but she is not morally creditworthy. But, setting that matter to one side, the problem for the Moral Reasons account arises even if we allow that Charity deserves some credit, because it remains clear that she is less creditworthy than Carey.

${ }^{40}$ You might think that, instead, the answer is: engaging in the general activity of helping others. But, actually, both answers are plausible. She pursues the general activity of helping others as an end, and she pursues helping Ned in particular as an end, too. I discuss this further below. 
The fact that Carey is guided by an attitude of care for Ned, and Charity is not, does not show up as a difference in how they are moved by the right-making factors. ${ }^{41}$

A proponent of the Moral Reasons account may respond in two ways. First, she may try to explain away our judgment that Carey is more deserving of moral credit than Charity. Second, she may try to show that, given the facts of the case, Carey is moved by the right-making factors to a greater extent than Charity. Let us consider how both of these responses could be developed. For the first, she might insist that our sense that Carey deserves more moral credit than Charity for helping Ned rests on a misapplied admiration of Carey's character. We admire how Carey is generally well disposed toward Ned, how she would treat Ned well in a wide range of situations and Charity would not. We mistakenly register this admiration of her character - rooted in our sense of how she would be motivated to act in other situations - as a judgment that she deserves more credit on account of more fully acting from the right kinds of motives in helping Ned.

This response fails to appreciate the direct role that individual-directed attitudes play in our motives. It assumes that the morally commendable features of Carey's mind that go beyond her noninstrumental motivation to help Ned are not aspects of her motives. But my conception of how individualdirected attitudes can motivate our actions should disabuse us of this assumption. It is true that, in maintaining an attitude of care toward Ned, Carey is thereby disposed to be motivated in beneficent ways in other situations. But it is also true that her attitude of care is a part of what motivates her in this situation insofar as it is what leads her to be motivated to alleviate Ned's plight, and thus we can rationalize her action as one that she performs for Ned's sake. So, we cannot explain away our moral commendation of Carey as a judgment of something beyond her motives and moral creditworthiness.

The other option for the Moral Reasons account is to show how Carey is actually motivated by the right-making factors to a greater extent than Charity, despite my initial claims otherwise. To do this, the proponent of the Moral Reasons account may suggest that Charity is only instrumentally motivated to help Ned, on the grounds that she helps him merely as a means to the end of engaging in some general activity she enjoys - the activity of helping others. But the fact that Charity's ultimate interest lies in the general activity of helping others does not imply that she is only instrumentally motivated to help Ned. To think this wrongly supposes that whenever we are motivated to do something as an instance of some more general activity that we enjoy, we are motivated to do it merely as a means to some further end. To see why this

${ }^{41}$ You might wonder, despite how Charity and Carey are motivated by the same right-making factor, whether Carey is more strongly motivated by that factor and so more fully acts from the right kinds of motives. But I do not see any reason for thinking this is so rather than thinking that Charity is more strongly motivated to help Ned than Carey, or that their motivations are of equal strength. 
supposition is false, think about your most recent exciting philosophical conversation. Presumably, your interest in that conversation stemmed from your more general interest in doing philosophy. ${ }^{42}$ But you were still motivated to engage in that conversation for its own sake, as an end. The same seems true of Charity: she enjoys helping others in general, she sees helping Ned as an instance of helping others, so she pursues helping Ned as an end.43

Therefore, I do not think that the Moral Reasons account can make sense of the Charity-Carey case. This is one example of a wider range of cases in which an agent's failure to be moved by a direct concern for others seems to diminish her moral creditworthiness even though she is noninstrumentally motivated by the right-making factors. These cases present a general problem for the Moral Reasons account: if the right kinds of motives at least sometimes require being guided by appropriate attitudes of regard for others, and if (as I argued earlier, and these cases illustrate) being noninstrumentally motivated by the right-making factors is generally insufficient for being guided by such attitudes, then the Moral Reasons account cannot fully capture what the right kinds of motives are.

But now you might wonder whether there is a natural way of modifying the Moral Reasons account so that it better captures how individual-directed attitudes figure into the right kinds of motives. What we would need from this modified account is an explanation of how important differences in whether agents are guided by such attitudes quite generally entail differences in how well their motives align with moral considerations. The most promising suggestion along these lines is due to the Kantian theories of the right kinds of motives developed by Christine Korsgaard (1996b) and Philip Stratton-Lake (2000). Both divide an agent's motives into two parts: the agent's purpose, and the principle according to which she chooses that purpose. Call the former the "purpose part" of her motives, and the latter the "principle part." The idea is that, whenever we choose some purpose, we do so on the basis of accepting some principle that calls for (or at least allows) pursuing such a purpose in one's circumstances. In this way, the principle part of an agent's motives serves

42 This is closely related to the main point made in Korsgaard (1983). Basically, I am suggesting that Korsgaard's distinction between extrinsic and instrumental goodness can be mirrored in an agent's motivations: an agent may be extrinsically motivated to perform some action $A$ (because she sees $A$ as an instance of some general, intrinsically valuable thing) and yet pursue $A$ noninstrumentally, as an end.

${ }^{43}$ Here, the proponent of the Moral Reasons account might turn our attention back to Carey and suggest, alternatively, that Carey is more fully motivated by the right-making factors insofar as she is more directly concerned for Ned's welfare. Charity's desire for Ned's welfare is somewhat indirect; it is simply a "realizer" of her more general desire to help others (Arpaly and Schroeder (2013: 105)). But why would this suggest that Carey is more fully motivated by the right-making factors than Charity? Presumably, what makes it right for Charity and Carey to help Ned is not ultimately the fact that Ned needs help but something more general, such as the fact that Ned is a fellow person (or creature) whom they are in a good position to help. This would suggest that, between the two of them, it is Charity, not Carey, who more fully incorporates the right-making factors into her motives. 
as a test for the practical eligibility of her purposes: it lays down the conditions for why and when her purposes are to be pursued. An agent can accept one of two such general principles, according to Korsgaard and Stratton-Lake: a principle of satisfying one's inclinations or a principle of complying with one's moral duty (which is to be understood in terms of the Kantian idea of universal willing, but we can set that aside here). So for any given choice, an agent will choose to pursue some purpose $P$ in light of taking her proposed pursuit of $P$ to satisfy either her inclinations or her moral duty. This means that our rationalization of an agent's action will have to appeal to both the purposes she pursues and the principle on the basis of which she chooses those purposes.

The Kantian modification of the Moral Reasons account thus provides an expanded conception of how an agent's motives should align with moral reasons. Her purposes must match the right-making factors, and the principle by which she chooses these purposes must be the principle of duty. Thus, on this Kantian Moral Reasons account, an agent who is noninstrumentally motivated by all of the right-making factors might still fail to (fully) act from the right kinds of motives, because she might choose those factors as her purposes on the basis of the wrong principle - the principle of inclination rather than duty.

Even so, the Kantian Moral Reasons account does not succeed in capturing the Charity-Carey case. The Kantian Moral Reasons account would need to claim that Carey chooses the purpose of helping Ned on the basis of the principle of duty while Charity does so on the principle of inclination. And it seems that, given the facts of the case, neither Carey nor Charity is motivated to help Ned on the basis of the principle of duty. For Carey is guided by an attitude of care for Ned, and we are often motivated by our sympathetic concern for others without averting to the principle of duty, and Charity is guided by her inclination-based interest in helping others. ${ }^{44}$ Perhaps, though, the Kantian Moral Reasons account could locate Carey's commitment to the principle of duty, not in her choice to help Ned, but in her more general concern for him and his plight - her attitude of care for him taken as a whole. That is, if she really is sympathetically concerned for him in a way that makes her firmly disposed to take his interests into account and treat him well in a wide range of situations, then, even if her choice to help him in this case does not specifically involve the principle of duty, her overarching attitude of care for him does.

I think this suggestion brings the Kantian Moral Reasons account very close to the Moral Attitudes account - too close, in fact. The problem is this: however we describe the commitment to the principle of duty that Carey's attitude of care involves, it will need to be the same general commitment to

44 Now, some theorists think that being motivated by care generally contrasts with motivation by duty - see, e.g., Slote (2001, ch. 1) and, perhaps, Held (2006). I think these theorists go too far: it seems to me that, in some cases, caring for someone moves us to act only through the recognition of how duty requires us to attend to them. But this is not a general feature of care, and so my point here still stands. 
duty that an attitude of interpersonal respect involves; for we can be committed to just one principle of duty (at least on the Kantian Moral Reasons account ${ }^{45}$ ). But then we will need some explanation of how a commitment to the principle of duty can issue in conflicting motives, given that the motives of care (e.g., to help someone) are sometimes incompatible with the motives of respect (e.g., to abide by others' wishes to be left alone). Now, a Kantian is not without resources for answering this question - think, in particular, of Kant's claim that the Formula of Humanity entails a commitment both to respect the ends that rational agents set for themselves and to take steps to promote their ends (Kant (2002/1785: 46-49)) - but I think that any full answer will end up appealing to the nature of our different attitudes of interpersonal care and respect. For to understand why a commitment to the principle of duty can issue in conflicting motives depending on whether it is embodied in an attitude of care or an attitude of respect, we will need to appeal to the differing structure and normative standards of those attitudes. ${ }^{46}$ Thus, the Kantian's answer will move us from the Kantian Moral Reasons account to (what would be) a Kantian Moral Attitudes account, which would say, in effect, that acting from the right kinds of motives consists in choosing purposes that incorporate rightmaking factors on the basis of the principle of duty in virtue of being guided by the different individual-directed attitudes that embody a commitment to that principle.

Therefore, I do not think that the Moral Reasons account can be made to explain cases such as Charity-Carey. These cases show how being guided by a direct concern for others both goes beyond being noninstrumentally motivated by the right-making factors and is at least sometimes required for deserving moral credit. Even when we try to modify the Moral Reasons account to capture aspects of an agent's motives beyond her motivation by the rightmaking factors, we cannot explain the full significance of her appropriate attitudes of regard for others without treating those attitudes as a basic component of the right kinds of motives (i.e., without drawing on the Moral Attitudes account). What is most important about Carey's motives is the appropriate

45 A Rossian Moral Reasons account might be more promising, insofar as we could plausibly imagine the different attitudes of respect and care involving an overarching commitment to different "prima facie" moral duties (Ross (2002)). The question about how such a view compares to the Moral Attitudes account would arise from cases in which we compare two agents who are motivated by different attitudes corresponding to different of Ross' prima facie moral duties, and one of the agents seems to deserve more moral credit than the other. Does this comparative judgment ultimately rest on our sense of which of the competing prima facie moral duties is more important, or rather our sense of which attitude is more morally appropriate? If, as I suspect, the latter is true, then the Moral Attitudes account remains our best option. But I am not able to investigate this matter here.

46 Theorists such as Robin Dillon (1992) and Kyla Ebels-Duggan (2008) would contend that interpersonal attitudes of respect and care are not so far apart, and so there is no problem here for the Kantian Moral Reasons account. But I think that, even if Dillon and Ebels-Duggan are correct, the Kantian Moral Reasons account will still collapse into a Kantian Moral Attitudes account because it will still need an independent account of the structure and normative standard of appropriate attitudes of regard for others. 
attitude of care for Ned that guides her action, and not just the fact that she is moved by the consideration that Ned needs her help. What this suggests is that our judgments of moral creditworthiness are ultimately concerned with our individual-directed attitudes themselves, as the Moral Attitudes account claims, and not just with the moral considerations that these attitudes dispose us to take into account, as the Moral Reasons account says.

\section{4.}

To conclude, I should be clear that I have not been arguing that being moved by moral reasons does not matter at all for moral creditworthiness. I think it matters, but only as a symptom of something more fundamental: responding to the individuals impacted by our actions through being guided by appropriate attitudes of regard for them. In thinking of the right kinds of motives in this individuals-first way, rather than the reasons-first way proposed by the Moral Reasons account, we can account for the creditworthiness of both agents such as Carey, whose attitudes of care for others are front and center in our assessment of whether they deserve moral credit, and agents such as Anthony, whose attitudes of regard for others tend to fade into the background.

I think that my treatment of these cases can serve as a useful reminder of a lesson that P. F. Strawson (2008) taught us about moral responsibility: that our assessments of moral responsibility are, at bottom, assessments of persons' "quality of will" toward one another, given that the reactive attitudes of resentment, indignation, and praise are most fundamentally attuned to persons' quality of will. My account can be understood as providing a conception of what constitutes quality of will and, accordingly, of what our responsibility assessments are tracking. Of course, the Moral Reasons account can draw a similar connection to Strawsonian theories of moral responsibility insofar as they, too, can try to lay claim to Strawson's idea of quality of will. But there is a way in which my account more readily and fully captures Strawsonian quality of will, given that when, e.g., we resent someone for cutting in front of us in line, we are most directly concerned with how they disrespected us and less directly concerned with how their disrespect manifested a lack of concern for the rightmaking factors that ruled out cutting in line. This, anyway, is how my account fits naturally into a broader picture of moral responsibility that I think provides a compelling explanation of the basis of our judgments of moral responsibility, including our judgments of whether persons act from the right kinds of motives. 47

${ }^{47}$ Many thanks to Samuel Asarnow, Michael Bratman, Jorah Dannenberg, David Hills, R. J. Leland, Julia Markovits, Benjamin Miller, Tamar Schapiro, Manuel Vargas, Han van Wietmarschen, and Allen Wood for their generous comments on (sometimes several) previous drafts of this paper, to many others for helpful conversations, and to two anonymous referees for the Journal of Ethics and Social Philosophy for their constructive suggestions. 
Grant J. Rozeboom

St. Norbert College

Donald J. Schneider School of Business and Economics

grant.rozeboom@snc.edu 


\section{References}

Anderson, E. (1993) Value in Ethics and Economics, Cambridge, MA: Harvard University Press. Arpaly, N. (2015) "Moral Worth and Normative Ethics," Oxford Studies in Normative Ethics, Vol. 5, pp. 86-104.

(2003) "Moral Worth," Unprincipled Virtue, New York: Oxford University Press, pp. $67-$ 115. and Schroeder, T. (2013) In Praise of Desire, Oxford: Oxford University Press.

Benhabib, S. (1985) "The Generalized and the Concrete Other: The Kohlberg-Gilligan Controversy and Feminist Theory," Praxis International 5(4): 402-24.

Bicchieri, C. (2006) The Grammar of Society: The Nature and Dynamics of Social Norms, Cambridge: Cambridge University Press.

Cohen, J. (2010) Rousseau: A Free Community of Equals, New York: Oxford University Press.

Darwall, S. L. (2014) "Being With," Honor, History, and Relationship: Essays in Second-Personal Ethics II, Oxford: Oxford University Press. (2006) The Second-Person Standpoint, Cambridge, MA: Harvard University Press. (2002) Welfare and Rational Care, Princeton: Princeton University Press.

Davidson, D. (2001) “Actions, Reasons, and Causes," Essays on Actions and Events, New York: Oxford University Press, pp. 3-20.

Dillon, R. S. (1992) "Respect and Care: Toward Moral Integration," Canadian Journal of Philosopby 22(1): 105-32.

Ebels-Duggan, K. (2008) “Against Beneficence: A Normative Account of Love," Ethics 119(1): 142-70.

Held, V. (2006) The Ethics of Care: Personal, Political, and Global, Oxford: Oxford University Press.

Herman, B. (1993) "On the Value of Acting from the Motive of Duty," The Practice of Moral Judgment, Cambridge, MA: Harvard University Press, pp. 1-22.

Hill, T. E. Jr. (1997) Respect for Humanity, Tanner Lectures on Human Values. (1992) Dignity and Practical Reason in Kant's Moral Theory, Ithaca, NY: Cornell University Press.

Hills, A. (2009) “Moral Testimony and Moral Epistemology,” Ethics 120(1): 94-127.

Hursthouse, R. (2000) On Virtue Ethics, Oxford: Oxford University Press.

Kant, I. (2002/1785) Groundwork for the Metaphysics of Morals, A. W. Wood, trans. and ed., New Haven, CT: Yale University Press.

Korsgaard, C. M. (2008) Self-Constitution: Agency, Identity, and Integrity, Oxford: Oxford University Press.

(1996a) The Sources of Normativity, New York: Cambridge University Press.

(1996b) "Kant's Analysis of Obligation: The Argument of Groundwork I," in Creating the Kingdom of Ends, New York: Cambridge University Press, pp. 43-76. (1983) "Two Distinctions in Goodness," The Philosophical Review 92(2): 169-95.

Markovits, J. (2010) “Acting for the Right Reasons," The Philosophical Review 119(2): 201-42.

Massoud, A. (2016) "Moral Worth and Supererogation," Ethics 126(2): 690-710.

McKenna, M. (2016) "Quality of Will, Private Blame and Conversation: Reply to Driver, Shoemaker and Vargas," Criminal Law and Philosophy 10(2): 243-63. (2012) Conversation and Responsibility, Oxford: Oxford University Press.

Neuhouser, F. (2014) Rousseau's Critique of Inequality: Reconstructing the Second Discourse, Cambridge: Cambridge University Press.

Noddings, N. (1984) Caring: A Feminine Approach to Ethics and Moral Education, Berkeley, CA: University of California Press.

Railton, P. (2006) "Normative Guidance," in R. Shafer-Landau, ed., Oxford Studies in Metaethics, Vol. 1, pp. 3-34.

Raz, J. (2006) "The Problem of Authority: Revisiting the Service Conception," Minnesota Law Review 90: 1003-44. (1986) The Morality of Freedom, Oxford: Oxford University Press.

Ross, D. (2002) The Right and the Good, Oxford: Oxford University Press. 
Scheffler, S. (2010) "Valuing," Equality and Tradition: Questions of Value in Moral and Political Theory, Oxford: Oxford University Press, pp. 15-40.

Shoemaker, D. (2013) “Qualities of Will," Social Philosophy and Policy 30(1-2): 95-120.

Slote, M. (2001) Morals from Motives, Oxford: Oxford University Press.

Smith, H. M. (1991) "Varieties of Moral Worth and Moral Credit," Ethics 101(2): 279-303.

Smith, M. (2004) "The Possibility of Philosophy of Action," Ethics and the A Priori: Selected Essays on Moral Psychology and Meta-Ethics, New York: Cambridge University Press, pp. 155-80.

Sorensen, K. (2009) "Effort and Moral Worth," Ethical Theory and Moral Practice 13(1): 89-109.

Sripada, C. and Stich, S. (2007) "A Framework for the Psychology of Norms," in P. Carruthers, S. Laurence and S. Stitch, eds., The Innate Mind: Culture and Cognition, Vol. 2, Oxford: Oxford University Press, pp. 1-34.

Stocker, M. (1981) "Values and Purposes: The Limits of Teleology and the Ends of Friendship," The Journal of Philosophy 78(12): 747-65.

Strawson, P. F. (2008) "Freedom and Resentment," Freedom and Resentment and Other Essays, New York: Routledge, pp. 1-28.

Stratton-Lake, P. (2000) Kant, Duty, and Moral Worth, New York: Routledge.

Thompson, M. (2004) "What Is It to Wrong Someone? A Puzzle about Justice," in R. J. Wallace, P. Pettit, S. Scheffler and M. Smith, eds., Reason and Value: Themes from the Moral Philosophy of Joseph Raz, Oxford: Oxford University Press, pp. 333-84.

Velleman, J. D. (2008) "The Gift of Life," Philosophy and Public Affairs 36(3): 245-66. (1999) "Love as a Moral Emotion," Ethics 109(2): 338-74.

Wasserman, D. (2005) "The Nonidentity Problem, Disability, and the Role Morality of Prospective Parents," Ethics 116(1): 132-52.

Zimmerman, M. J. (1988) An Essay on Moral Responsibility, Rowman \& Littlefield. 